\title{
Joachim Perels Zur politischen Verfassung des Sozialismus
}

\begin{abstract}
Fehltritte, die cine wirklich revolutionäre Arbeiterbewegung begeht, sind geschichtlich unermeßlich fruchtbarer und wertvoller als die Unfehlbarkeit des allerbesten $*$ Zentralkomitees $\alpha$.
\end{abstract}

Rosa Laxemburs

\section{Vorbemerkung}

Der Begriff des Sozialismus ist innerhalb der Linken kontrovers. Die KP-orientierte Position identifiziert die Verhältnisse in den "sozialistischen Ländern" Osteuropas mit dem von Marx intendierten Sozialismus: Verstaatlichung der Produktionsmittel, gesamtwirtschaftliche Planung und die führende Rolle der Partei geten als Inbegriff des Sozialismus. Gegenüber diesen Bestimmungen gerät das zentrale Marxsche Ziel, die Aufhebung des Lohnarbeitsverhültnisses und die daraus folgenden Veränderungen in der politischen Verfassung aus dem Blickfeld. Mit dem nachstehenden Aufsatz soll versucht werden, den Rahmen für eine an der Marxschen Emanzipationsdimension orientierte Analyse des osteuropäischen Sozialismus abzustecken. Der Aufsatz versteht sich als die gleichsam andere Seite der auf den Kapitalismus bezogenen marxistischen Staatstheorie.

\section{Zur Theorie von Marz und Engels}

Die Konstituierung des Sozialismus folgte für Marx und Engels nicht aus einem abstrakten Postulat, das - wie bei den utopischen Sozialisten - als Modell abseits vom Geschichtsprozeß konstruiert wurde. Vielmehr trieb die Analyse des Kapitalismus seine Verfallsbedingungen hervor, aus denen »mit der Notwendigkeit eines Naturprozesses "1 die sozialistische Produktionsweise entstehen sollte. Sie erscheint als bestimmte Negation des Kapitalismus und seiner politischen Yerfassung.

In seiner frühen Schrift „Zur Judenfrage», in der Marx die in den bürgerlichen Interessenhorizont festgebannte Französische Revolution analysierte und die bloß politisclse Emanzipation des Dritten Standes gegen die menschliche Eman-

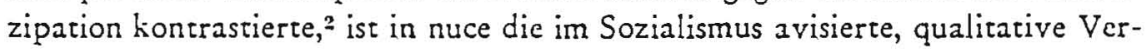

1 K. Marx, Das Kapital I, Berlin 1962 (= MEW 23), S. 79r. Das in dieser Formulierung cingekapselte Problem der Beziehung von objektivem und subjektivem Faktor fällt aus dem Rahmen unserer Erörterungen heraus. Zu der in der Marxschen Theorie explizit nicht aufgelösten Problematik des Verhältnisses des hegelianischea Geschichrsobjektıvismus und der fresen Tat des Proletariats vgl. erwa K. Korsch, Karl Mara, Frankfurt/Wien 1967, S. Ij6 f.

- K. Marx, Zur Judenfrage, in: Frühe Schriften, ed. Lieber, Stuttgart r962, S. 4óg.

- Die politische Revolution löst das bürgerliche Leben in seine Bestandecile auf, ohne dicse Bestandreile selbse zu revolutionieren und der Kritik zu unterwerfen. Sie verhält sich zur Lürgerlichen Gesellschaft, zur Welt der Bedürfnisse, der Arbeit, der Privatinteressen, als zur Grundlage ihres Bestehens, als zu einer nicht weiter begründeten Voraussetzung, daner als zu ihrer Naturbasis.e Ebend1, S. 479. 
änderung der Kommunikationsbeziehungen der Individuen und die hieraus abgeleitete tendenzielle Aufhebung der politischen Gewalt bezeichnet: „Erst wenn der wirkliche individuelle Mensch den abstrakten Staatsbürger in sich zurücknimmt und als individueller Mensch in seinem empirischen Leben, in seiner individuellen Arbeit, in seinen individuellen Verhältnissen, Gattungstuesen geworden ist, erst wenn der Mensch seine sforces propress als gesellschaftliche Kräfte erkannt und organisiert hat und daher die gesellschaftliche Kraft nicht mehr in Gestalt der politischen Kraft von sich trennt, erst dann ist die menschliche Emanzipation vollbracht. «3

Die kapitalistischen Produktionsverhältnisse sind das reale Reversbild der von Marx antizipierten "menschlichen Emanzipation". In ihnen sind die "forces propres der Menschen nicht bewußt als gesellschaftliche organisiert, sondern zu isoliert privaten dissoziiert. Diese Zerrissenheit gründer in der Warenform der Produktion, die den gesellschaftlichen, kooperativen Charakter der Arbeit nicht in ihr selbst, sondern erst nachträglich im Tausch der Arbeitsprodukte erscheinen läßt.t Der "Fetischcharakter der Ware", der "den Menschen die gesellschaftlichen Charaktere ihrer eigen n Arbeit als gegenständliche Charaktere der Arbeitsprodukte selbst, als gesellschaftliche Natureigenschaften dieser Dinge zurückspiegelt ${ }^{5}$, kann nur entstehen, weil die Privatarbeiten unabhängig voneinander betrieben werden, das heißt sich nur im naturwüchsigen Tausch der Arbeitsprodukte aufeinander beziehen. $\gg$ Den [...] [Produzenten] erscheinen [...] die gesellschaftlichen Beziehungen ihrer Privatarbeiten als das, was sie sind, d.h. nicht als unmittelbar gesellschaftliche Verhältnisse der Personen in ihren Arbeiten selbst, sondern vielmehr als sachliche Verhältnisse der Personen und gesellschaftliche Verhältnisse der Sachen. $\times^{6}$ Die auf diese Weise dissoziierten Individuen stehen unter der Kontrolle ihrer Produkte, statt sie zu kontrollieren. ${ }^{7}$ Die Zerreißung von Allgemeinem und Besonderem, d. h. die Annektierung des Besonderen, der individuellen Arbeit, durchs abstrakt Allgemeine, der Herrschaft des Tauschwerts über den Gebrauchswert, ${ }^{72}$ kristallisiert sich im antagonistischen Verhältnis der kapitalistischen Produktion, im Verhältnis von Kapital und Lohnarbeit. Dem Kapital, dessen Selbstverwertung der Zweck der Warenproduktion ist, gehören die Produktionsmittel; die Lohnarbeit, Bedingung der Existenz des Kapitals, ist von den Produktionsmitteln getrennt: die unmittelbaren Produzenten besitzen nur ihre Arbeitskraft, die sie, um leben zu können, ans Kapital veräußern. Die unmittelbaren Produzenten werden zu entfremdeten Momenten des ihrer Verfügung entzogenen Produktionsapparates, »ebenso Zubehör des Kapitals als das tote Arbeitsinstrument « ${ }^{8}$. "Einerseits verwandelt der Produktionsprozeß fortwährend den stofflichen Reichtum in $\mathrm{Ka}$ pital, in Verwertungs- und Genußmittel für den Kapitalisten. Andercrseits

3 Ebenda, S. 479. Hervorhebungen von Marx.

4 K. Marx, Das Kapital I, a. a. O., S. S7. Vgl. auch zum folgenden, H. J. Krahl, Zur Wesenslogik der Marxschen Warenanalyse, neue kritik, ss/s6 (rg70), S. : 8 ff.

5 K. Marr, Das Kapital I, 2. a. O., S. 86.

- Ebenda, S. 87

Ebenda, S. 89.

is Der Gebrauchswere, der als konkreter Gesenstand sein besonderes Bedürfnis befriedigt a (ebenda, S. s6), wird in der Warencroduktion, deren immanentes Gesecz die Produktion für den Tausch ist, zum Anhängsel des Tauschwerts: $>$ Im Wereausdruck der Leinwand besteht die Nützlichkeit der Schneiderei niche darin, daß sie Kleider, also auch Icute, sondern daß sie einen Körper macht, dem man es ansieht, daß er Were ista (ebend2, S. 72); $>$ die konkrete Arbsic [wird] zur Erscheinungsform ihres Gegenteils, abstrakt menschlicher Arbeit.a Ebenda, S. 73 .

8 Ebenda, S. 598. 
kommt der Arbeiter beständig aus diesem Prozeß heraus, wie er in ihn eintrat persönliche Quelle des Reichtums, aber entblößt von allen Mitteln, diesen Reichtum für sich zu verwirklichen. Da er vor seinem Eintritt in den Prozeß seine eigene Arbeit ihm selbst entfremdet, dem Kapitalisten angeeignet und dem Kapital einverleibt hat, vergegenständlicht sie sich während des Prozesses beständig im fremden Produkt. Da der Produktionsprozeß zugleich Konsumtionsprozeß der Arbeitskraft durch den Kapitalisten, verwandelt sich das Produkt des Arbeiters nicht nur fortwährend in Ware, sondern in Kapital, Wert, der die wertschöpfende Kraft aussaugr, Lebensmittel, die Personen kaufen, Produktionsmittel, die den Produzenten anwenden. Der Arbeiter selbst produziert daher beständig den objektiven Reichtum als Kapital, ihm fremde, ihn beherrschende und ausbeutende Macht, und der Kapitalist produziert ebenso beständig die Arbeirskraft als subjektive, von ihren eigenen Vergegenständlichungs- und Verwirklichungsmitteln getrennte, abstrakte, in der bloßen Leiblichkeir des Arbeiters exiscierende Reichrumsquelle, kurz den Arbeiter als Lohnarbeiter. «?

Die Aufhebung des Kapitalverhältnisses, in dem die Arbeiter, Objekr eines antagonistischen Verhältnisses, von ihren weigenen Vergegenständlichungs- und Verwirklichungsmitteln * getrennt sind, geschieht durch die Expropriation der Expropriateure, ${ }^{10}$ die Ersetzung des Kapitals durch die assoziierten Produzenten, die »mit gemeinschaftlichen Produktionsmitteln arbeiten und ihre vielen individuellen Arbeitskräfte selbstbewußt als gesellschaftliche Arbeitskraft verausgaben " 11 .

Der Fetischcharakter der Warenproduktion, der die Individuen zu Anhängseln dez Zwangsgesetze des Tauschverkehrs degradiert, wäre überwunden in einer planmäßig auf die Bedürfnisse der Menschen gerichteten Produkrionsweise, in der der $\gg$ Mensch sein[e] iforces propres« als gesellschafrliche Kräfte erkannt und organisiert hat ${ }^{12}$, die assoziierten Produzenten [...] ihren Stoffwechsel mit der Natur rationell regeln, unter ihre gemeinschaftliche Kontrolle bringen, statt von ihm als von einer blinden Macht beherrscht zu werden ${ }^{13}$.

Mit der Aufhebung der antagonistischen kapitalistischen Produktionsverhältnisse verändert sich die politische Verfassung, weil »der Mensch [...] die geselischaftliche Kraft niche mehr in Gestalt der politischen $\mathrm{K}_{\text {raft }}{ }^{14}$ von sich zu trennen genötigt ist. War der Staat die Gestalt des vorgeblich klassenjenseitigen, »illusorische[ $\mathrm{n}$ ] Allgemeininteresses ${ }^{15}$, »die Zusammenfassung der bürgerlichen Gesellschaft $\aleph^{18}$, „die Organisation, welche sich die bürgerliche Gesellschaft gibr, um die allgemeinen äußeren Bedingungen der kapitalistischen Produktionsweise aufrecht zu erhalten gegen Ubergriffe sowrohl der Arbeiter als auch einzelner Kapitalisten ${ }^{17}$, so verschwindet der Staat im Kommunismus als der Gesellschaftsformation, die nicht mehr von antagonistischen Interessen zerrissen ist, die durch eine öffentliche Gewalt gezähmt werden müßten. „Die bisherige, sich in Klassengegensätzen bewegende Gesellschaft hatte den Staat nötig, d. h.

- Ebenda, S. s9s f.

10 Ebenda, S. $79 x$.

11 Ebenda, S. 92.

12 K. Marx, Zur Judenfrage, a. a. O., S. 479.

13 K. Marx, Das Kapital III, Berlin 1964 (= MEW 25), S. 828.

It K. Marx, Zur Judenfrage, a. a. O., S. 479.

15 K. Marx/F. Engels, Die deursche Ideologie, Berlin r 960, S. 63.

16 K. Marx, Grundrisse der Kritik der politischen Okonomie, Berlin r953, S. 29 f.

17 F. Engels, Die Entwicklung des Sozialismus von der Utopie zur Wissenschaft, Frankfurt/M. 1946, S. 40. Eine materialistische Analyse des Verhälnnisses von Basis (kapitalistische Produksionsverhäitnisse) und Uberbau (Sraat, Rechr, Ideologie) kann an dieser Srelle nicht gelesster werden. 
eine Organisation der jedesmaligen ausbeutenden Klasse zur Aufrechterhaltung ihrer äußeren Produktionsbedingungen, also namentlich zur gewaltsamen Niederhaltung der ausgebeuteten Klasse in den durch die bestehende Produktionsweise gegebenen Bedingungen der Unterdrückung (Sklaverei, Leibeigenschaft oder Hörigkeit, Lohnarbeit) [...] Sobald es keine Gesellschaftsklasse mehr in der Unterdrückung zu halten gibt, sobald mit der Klassenherrschaft und dem in der bisherigen Anarchie der Produktion begründeten Kampf ums Einzeldasein auch die daraus entspringenden Kollisionen und Exzesse beseitigt sind, gibe es nichts mehr zu reprimieren, das eine besondere Repressionsgewalt, einen Staat, nötig machte [...] Der Staat wird nicht abgeschafft, er stirbt ab. «18 "Die Gesellschaft, die die Produktion auf Grundlage freier und gleicher Assoziation der Produzenten neu organisiert, versetzt die ganze Staatsmaschine dahin, wohin sie dann gehören wird: ins Museum der Altertümer, neben das Spinnrad und die bronzene Axt. «19

Das Aufgehen der Staatsgewalt in der freien Assoziation der Produzenten ist allerdings an die Überwindung des in der sersten Phase der kommunistischen Gesellschaft fortwirkenden sengen bürgerlichen Rechtshorizonts « 20 und an die höchste Entfaltung der Produktivkräfte gebunden. In der »ersten Phase der kommunistischen Gesellschaft«, die noch »mit den Mutrermalen der alten Gesellschaft behaftet ist , besteht das "gleiche Recht « mit seiner »bürgerlichen Schranke * fort: obgleich das Privateigentum in genossenschaftliches übergegangen ist, regelt sich die Verteilung der individuellen Konsumtionsmittel nach gleichem Recht, proportional zu den Arbeitslieferungen der Produzenten. "Dies gleiche Recht ist ungleiches Rechr für ungleiche Arbeir. Es erkennt keine Klassenunierschiede an, weil jeder nur Arbeiter ise wie der andere; aber es erkennt stillschweigend die ungleiche individuelle Begabung und daher Leistungsfähigkeit als natürliche Privilegien an. Es ist daher ein Recht der Ungleichheit seinem Inhalt nach, wie alles Recht. $*^{21}$ Das Oberschreiten des bürgerlichen Verteilungssystems ist erst möglich, wachdem mit der allseitigen Entwicklung der Individuen auch die Produkrionskräfre gewachsen sind und alle Springquellen des genossenschaftlichen Reichtums voller fließen; erst dann kann der enge bürgerliche Rechtshorizont ganz überschritten werden und die Gesellschaft auf ihre Fahnen schreiben: Jeder nach seinen Fähigkeiten, jedem nach seinen Bedürfnissen ${ }^{22}$. Weitere Voraussetzungnfür das Aufgehen der politischen Gewalt in der Selbstbestimmung der assoziierten Individuen ist die Internationalisierung des Kommunismus, der »empirisch nur als die Tat der herrschenden Völker auf einmal und gleichzeirig möglich [ist], was die universelle Entwicklung der Produktivisraft und den mit ihr zusammenhängenden Weltverkehr voraussetzt. «23 In der Ubergangsperiode vom Kapitalismus zum Sozialismus besteht die öffentliche Gewalt in veränderter Funktion fort. Sie wird zum Instrument des Proletariats, das der Bourgeoisie die Produktionsmittel entzieht und sie seiner Verfügungsgewalt unterwirft. Die srevolutionäre Diktatur des Proletariats ${ }^{24}$, die Marx und Engels mit der Erkämpfung der Demokratie ${ }^{25}$ gleichsetzen, weil

\footnotetext{
18 Ebenda, S. 42. Hervorhebung von Engels.

19 F. Engels, Der Ursprung der Familie, des Privateigentums und des Stzztes, Stutrgart 1948, S. 96.

so K. Marx, Kritik des Gothaer Programms, in: Politische Schrifren II, ed. Lieber, Stuttgart 1960, S. 1024 .

21 Ebenda, S. 1022 ff.

$\because$ Ebenda, S. 1024 .

23 K. Marx / F. Engels, Die deursche Ideologie, a. 2. O., S. 32

26 K. Marx, Kritik des Gothzer Programms, 2. 2. O., S. 1034.

25 K. Marx / F. Engels, Manifest der Kommunistischen Partei, Berlin 1946, S. 23.
} 
die sproletarische Bewegung [...] die selbständige Bewegung der ungcheuren Mehrzahl im Interesse der ungeheuren Mehrzahl [ist] «" ist die politische Form für die Aufhebung des Kapitalverhältnisses.

In der Pariser Kommune nahn die Dilstatur des Proletariats Gestalt an. Die zur politischen Herrschaft gekommene Arbeiterklasse konnte $\bullet$ nicht die ferrige Staatsmaschine einfach in Besitz nehmen und diese für ihre eigenen $Z$ wecke in Bewegung setzen «"7. Denn die alte Staatsmaschine, ${ }^{2}$ Kriegswerkzeug des Kapitals gegen die Arbeit ${ }^{28}$, war für die spezifischen Formen bürgerlicher Herrschaft (Gewaltenteilung, Repräsentativsystem und Parlamentarismus) konstruiert. "Statt einmal in drei oder sechs Jahren zu entscheiden, welches Mitglied der herrschenden Klasse das Volk im Parlament ver- und zertreten soll, sollte das allgemeine Stimmrecht dem in Kommunen konstituierten Volk dienen. $\alpha^{29} \leadsto$ Die Kommune bildete sich aus den durch allgemeines Stimmrecht in den verschiedenen Bezirken von Paris gewählten Stadträten. Sie waren verantwortlich und jederzeit absetzbar [...] Die Kommune sollte nicht eine parlamentarische, sondern eine arbeitende Körperschaft sein, vollziehend und gesetzgebend zur gleichen Zeit. Die Polizei, bisher das Werkzeug der Staatsregierung, wurde sofort aller ihrer politischen Eigenschaften entkleidet und in das verantwortliche, jederzeit absetzbare Werkzeug der Kommune verwandelt. Ebenso die Beamten aller anderen Verwaltungszweige. Von den Mirgliedern der Kommune an abwärts mußte der öffentliche Dienst für Arbeiterlohn verrichtet werden [...] Wie alle übrigen öffentlichen Diener sollten sie [die richterlichen Beamten] fernerhin gewählt und jederzeit absetzbar sein. ${ }^{30}$ War die öffentliche Gewalt aus ihrer bürgerlichen Form und Scheinselbständigkeit gerissen, konnte daran gegangen werden, die gesellschaftliche Herrschaft der Bourgeoisie, der Charaktermasken des Kapitals, zu brechen - durch die »Enteignung der Enteigner «.31 Die Kommune, »Resultat des Kampfes der hervorbringenden gegen die aneignende Klasse, [war] die endlich entdeckte politische Form, unter der die ökonomische Befreiung der Arbeit sich vollziehen konnte «?2.

\section{Exemplarische Verfassungsprobleme der frühen Sowjetunion}

Zwischen I9r7 und I92I wurden von den Bolschewiki die zentralen Fragen der politischen Verfassung des Sozialismus theoretisch erörtert und praktisch in einer Weise gelöst, die in der späteren Struktur der osteuropäischen Länder zum sozialistischen Richtmaß erhoben wird.33 Für eine Analyse dieser Länder, die sich vom emanzipativen Gehalt der Marxschen Theoria und den rätesozialistischen Ansätzen der Oktoberrevolution leiten läßt, erscheint die Vergegenwärti-

26 Ebenda, S. is

a K. Mars, Der Bürgerkrieg in Frarkreich, in: Politische Schriften II, ed. Licber, Stuttgart 1960, S. $g 19$.

29 Ebencia, 5. 9:x.

23 Ebendz, S. 924 f.

is Ebend 3, S. 922 ff.

31 Ebeniz, S. 9:7.

32 Ebenda, S. 927.

35 Vgl. crwa die Anmerbungen c'es Dierz-Verlages Dertin (Ost) zu Lerins Ausgewähiten Wurken $(197=)$, in denen ron Lenin abrweichende Positionen inncrhalb der Bolschewiki a prori zu p parteifcindlichen erblärt werden (z. B. Bd. III, S. 934) - unabhängig auch von Lenıns eigenem Verhalten: Schlspnikow, Vertreter der dissentierenden $\rightarrow$ Arbeireropposition wurde z. B. auf Lenins Vorschlag nach der Auseinanderserzung auf dem X. Parteitag von r92I (im einzelnea hierzu unter b) ins $\mathrm{ZK}$ gewählt. 
gung der Diskussion und Praxis der frühen Sowjerunion insofern als notwendige Voraussetzung.

a) Räteverfassung und Avantgardefunktion der Partei

Die Frage der politischen Form für die ökonomische Emanzipation des Proletariats stand mit der bürgerlichen Februarrevolution von I9I7 in Rußland wieder auf der Tagesordnung. In den berühmten Aprilthesen von I 9 I 7 - mit denen Lenin die zweite [...] Etappe der Revolution, die die Macht in die Hände des Proletariats und der ärmsten Schichten der Bauernschaft legen a $^{34}$ soll, einleitet - wird, streng der Marxschen Tradition folgend, die Forderung nach einem - Kommunestaat «, "das heißt eines Staates nach dem Vorbild der Pariser Kommune $\alpha^{55}$, aufgestellt. Durch den »Ubergang [...] der gesamten Staatsmadat an die Sowjets der Arbeiterdepurierten ${ }^{36}$ nimmt die Kommune, Instrument für die Machtercberung durchs Proletariat und, gleichzcitig, die Regierungsform des Proletariats, welche die Trennwand zwischen Regierenden und Regierten aufhsbt, die Gestalt der Sowjets an. Entsprechend lauten die Forderungen: ఎAbschaffung der Polizei, der Armee, der Beamtenschaft (das heißt Ersetzung des stehenden Heeres durch die aligemeine Volksbewaffnung); Enclohnung aller Beamten, die durchweg wählbar und jederzeit absetzbar sein müssen, nicht über den Durchschnittslohn eines guten Arbeiters hinaus. "37 In seiner Schrift "Staat und Revolution", geschrieben im August 1917, nimmt Lenin seine Aprilthesen auf, erweitert sie zu einer auf die aktuellen Probleme der bevorstehenden Revolution bezogenen Rekonstruktion der Marx-Engelschen Staatstheorie. Indem sich die öffentliche Gewalt vermitrels der Sowjers zu einem Organ der ungeheuren Mehrheit des Volkes verwandelt, »beginnt der Staat abzusterben. An die Stelle besonderer Institutionen einer bevorzugten Minderheit (privilegiertes Beamtentum, Kommandobestand des Heeres) kann das die Mehrheit unmittelbar besorgen, und je größeren Anteil das gesamte Volk an der Ausübung der Funktionen der Staatsmacht hat, umso weniger bedarf es dieser Macht. ${ }^{38} \mathrm{Nach}$ dem Sturz der Kapitalisten und Beamten und der Übernahme der $\gg$ Rechnungslegung und Kontrolle durch die Arbeiter selbst «, hört der Staat auf, wein spolitischer Staat< zu sein, dann svertwandeln sich die öffentlichen Funktionen aus politischen in einfache, administrative Funktionen<. s $^{30}$

Die von Lenin antizipierte Rolle der Sowjets wird Wirklichkeit in der Oktoberrevolution, in der die Bolschewiki ihr Führungsmandat aus der Mehrheit in den Sowjets ableiten. In der Verfassung der Russischen Föderativen Sowjetrepublik vom Juli 1918 wird die Sowjetverfassung institutionalisiert: "Rußland wird als Republik der Arbeiter, Soldaten- und Bauerndeputierten erklärt. Die ganze zentrale und lokale Gewalt steht diesen Sowjets zu.* (Art. I Ziff. I).40 Die Sowjets ais Organe der Selbstregierung des Volkes verlieren allerdings schnell ihre Funktion: Einmal stärkt der in der Mitte des Jahres I 9 I 8 einsetzende Bürgerkrieg unmittelbar die Zentralgewalt und läßt durch das Verbot nicht-bol-

31 W. I. Lenin, Ober dic Aufgaben des Proletariats in der gegenwärtigen Revolution, in: Ausgewählte Werke in drei Bänden, Berlin 1970, Bd. II, S. 40.

35 Ebenda, S. 42.

so Ebenda, S. 4 I.

37 Ebenda, S. 4 r.

38 W. I. Lenin, Staat und Revolution, 2. 2. O., Bd. II, S. 353. Hervorhebung von Lenin.

so Ebenda, S. 402, Anm. 1.

to H. Conerr, Der Kommunismus in der Sowjetunion, Frankfurt 1971, S. 33. 
schewistischer Parteien gleichzeitig die freie Wahl der Kandidaten für die Sowjets allmählich schwinden. ${ }^{41}$ Neben diesen äußeren Umständen ist die Räteverfassung der russischen Republik durch das leninistisch bestimmte Verhältnis von Partei und Klasse mir ciner prinzipicllen Crux behafter (ein Problem übrigens, das in "Staat und Revolution « nicht thematisiert wird).42 In den Jahren 1902/ 1904 hatte Lenin einen auf die Erfordernisse des autokratisch regierten Zarismus bezogenen Parteitypus inauguriert, der die Partei zum konspirativen, berufsrevolutionären und zentralistisch organisierten "Vortrupp « machte, unter dessen »Leitung a die gesamte Klasse »in der Epoche des Bürgerkriegs« handeln sollte. ${ }^{43}$ Die immanenten Folgen der Theorie Lenins hatte Trotzki bereits 1904 antizipiert (ohne daß er nach der Oktoberrevolution diese Position beibehalten hätre $)^{\text {t4 }}$ : Durch die "politische [...] Substiturion des Proletariats « werde die Diktatur des Proletariats zu einer „Diktatur über das Proletariat«: „Nicht die selbständige Arbeiterklasse, die das Schicksal in ihre Hände nimmt, sondern die sstarke und mächrige Organisation،, die über das Proletariar und durch es über die Gesellschaft herrscht, wird den Ubergang zum Sozialismus sichern. ${ }^{45}$ Der Leninsche Parteitypus verwandelte sich nach der Oktoberrevolution in ein gewissermaßen staatsrechtliches Institut, welches den Bolschewiki das prinzipiell nicht weiter abzuleitende Führungsmandat, jenseits der in den Sowjets sich herausbildenden Selbstorganisationsformen, zusprach. Die Dialektik von Partei und Klasse wurde so in der Avantgardefunktion der Bolschewiki stillgelegt. Illusionslos stellte Lenin - unter Hinweis auf das niedrige Kulturniveau des Landes - im März I919 fest, »daß die Sowjets, die nach ihrem Programm Organe der Verwaltung durch die Werktätigen sein sollen, in Wirklichkeir Organe für die Werktätigen sind, eine Verwaltung durch die fortgeschrittene Schicht des Proletariats, nicht aber durch die werktätigen Massen selbst « ${ }^{46}$. Die ${ }^{\prime}$ fortgeschrittene Schicht des Proletariats - das ist die Partei der Bolschewiki, die, zumal bei den Sowjetwahlen nur Bolschewiki und regierungstreue Parteilose zugelassen sind ${ }^{4}$, ihre Herrschaft mit der Diktatur des Proletariats gleichserzt: "Die Diktatur der Arbeiterklasse [kann] nicht anders verwirklicht werden [...] als durch die Diktatur ihrer Vorhut, d.h. durch die Kommunistische Partei «\$ heißt es bei Sinowjew. »Die Räte-Demokratie wurde zur Hülle, die die Parteidiktatur verbarg. ${ }^{40}$ Die Diktatur der Partei über die Klasse ließ die politische Organisationsform für die ökonomische Befreiung des Proletariats leerlaufen. Rosa Luxemburg hat dies in ihrer Analyse der russischen Revolution scharf herausgearbeitet: "Lenin-Trotzki entscheiden sich [...] für die Diktatur im Gegensatz zur Demokratie und damit für die Diktatur einer Handvoll Personen, d. h. für Diktatur nach bürgerlichom Muster. [...] Es [das Proletariat]

11 A. Rosenber5, Geschichee des Bolschewismus, Frankfurt 1966, S. Iss f.

12 Vgi. L. Magri, Für eiaen neuen Realismus, in: I. Colletri u. a., Lenins > Seaat und Revolution * - heure, Berlin 1970, S. 52.

43 W. I. Lenin, Ein Schritt vorwärts, zwei Schritr zurück, a. a. O., Bd. I, S. 368 f. Vgl. auch ebenda, S. 490 sowie W. I. Lenin, Was tun?, a. 2. O., B. I., S. 252 f.

4t Vgl. zu seiner mit Lenin übereinstimmenden Haltung nach der Revolution: L. Trotzki, Terrorisnus und Kommunismus, Hamburg 1921 , S. 88.

15 L. Trotzki, Unsere politischen Aufgaben, in: Schriften zur revolutionären Orgaaisation, ed. Mehringer, Hamburg 1970, S. 68, S. 127.

to W. I. Lenın, Bericht über das Partciprogramm (auf dem VIII. Parteitag der KPR [B]), a. a. O., Bd. III, S. 200 . Hervorhebungen von Lenin.

47 A. Rosenberg, a. a. O., S. 156.

49 G. Sinowjew, Der Zentralismus, in: Kommunistische Rundschau, Jg. I Nr. I (1. 10. 1920), S. 27 f., zic. nach O. Anweiler, Einleitung zu F. Kool/ E. Oberländer (Hrsg.), Arbeiterdemokracie oder Parteidiktatur, Olten 1967, S. 56.

$19 \mathrm{~W}$. Abendroth, Sozialgeschichte der europäischen Arbeiterbewegung, Frankfurt 1965, S. 104- 
soll und muß [...] sofort sozialistische Maßnahmen in energischer, unnacligiebigster, rücksichtslosester Weise in Angriff nehmen, also Diktatur ausüben, aber Diktatur der Klasse, nicht einer Partei oder einer Clique, Diktatur der Klasse, d.h. in breitester Offentlichkeit, unter tätigster ungehemmter Teilnahme der Volksmassen, in unbeschränkter Demokratie [...]. Es ist die historische Aufgabe des Proletariats, wenn es zur Macht gelangt, anstelle der bürgerlichen Demokratie sozialistische Demokratie zu schaffen, nicht jegliche Demokratie abzuschaffen. ${ }^{50}$

Die Diktatur der Partei folgte freilich nicht nur aus bestimmten theoretischen Prämissen Lenins, sondern wurde durch die geschichrlichen Umstände nach dem Ende des Bürgerkriegs, der durch den Interventionskrieg kapitalistischer Staaten besonders verschärft wurde, direkt begünstigt. Das Land war verwüstet, * wirtschaftlich [...] um mehr als ein halbes Jahrhundert zurückgeworfen “; das Proletariat, ohnehin nur ein kleiner Teil des russischen Volkes, hatte wals geschlossene gesellschaftliche Macht zu existieren aufgehört. ${ }^{51}$ Diese Lage, der »authentische [...] Ursprung [...] der sogenannten bürokrarischen Degeneration des Regimes «52, ermöglichte die Substitution des Proletariats durch die alte Garde der Bolschewiki. Lenin war sich dieses Tatbestandes völlig bewußt. Im März I 922 notierte er: "Wenn man seine Augen nicht vor der Wirklichkeit verschließen will, so sollte man zugeben, daß der proletarische Charakter der von der Partei betriebenen Politik gegenwärtig nicht von der Klassenzusammensetzung der Mitgliedschaft bestimme wird, sondern von der enormen und ungeteilten Autorität jener sehr dünnen Schicht von Mitgliedern, die sich als die alte Garde der Partei beschreiben lassen. «53

\section{b) Zur Veränderung der Produkrionsverhälınisse nach der Revolution}

Wie die politische Verfassung der Sowjetunion ihr emanzipatives Versprechen uneingelöst ließ, so blieben auch die mit einer sozialistischen Revolution intendierten qualitatipen Veränderungen der Beziehungen der Individuen im ökonomischen Bereich mit prinzipiellen Schwierigkeiten behafter. Die von Lenin - im Gefolge von Marx - vorausgesetzte Internationalisierung der sozialistischen Revolution, die nach dem Durchbrechen des »schwächsten Gliedes « des Kapitalismus in Rußland die Entfaltung der Produktivkräfte auf der Basis eines zumindest europäischen Sozialismus sichern sollte, blieb aus. Lenin hatte im Mai 19 I 8 ausdrücklich erklärt: "Wir verschließen nicht die Augen davor, daß es uns allein - der sozialistischen Revolution in einem Land, selbst wenn dieses viel weniger rückständig wäre als Rußland, selbst wenn wir in leichteren Verhältnissen lebten als nach vier Jahren eines unerhörten, qualvollen, schweren und verheerenden Krieges - nicht möglich ist, mit den eigenen Kräften die sozialistische Revolution in einem Land voll durchzuführen. «54 Die Rückständigkeit des Landes, die sich besonders im Uberwiegen der Bauernwirtschaft mit ihrer durch

50 R. Luxemburg, Die russische Revolution, Frankfurt 1963, S. 77 f. Erste Hervorhebung von mir, zweite von Luxemburg.

31 I. Deutscher, Die unvollendete Revolution 1917-1967, Frankfurt 1967, S. 38.

s: Ebenda, S. 39.

ss W. I. Lenin, Sotschinenija, Bd. XXIII, S. 229 ff., zit. nach I. Deutscher, Trotzli II. Stutegart 1963, S. 32. Zur Frage der Substitution der Proletariats durch die Partei vgl. T. Cliff, Revoluesonäre Parteı und Klasse, Sozialistische Correspondenz, Frankfurt 1970, Nr. 56/57, S. $23 \mathrm{ff}$.

54 W. I. Lenin, Rede auf dem ersten Kongreß der Volkswirtschafisräte, a. a. O., Bd. II, S. 827. 
die Landaufteilung begünstigten individualistischen Kleinwarenproduktion ausdrückte, ließ die Entfaltung sozialistischer Produktionsverhältnisse gegenüber der Entwicklung der Produktivkräfte zurücktreten. So wurden in dieser primär auf die Produktionsentwicklung gerichteten Periode die Ursachen gesetzr für eine Verengung des Begriffs des Sozialismus auf einen vom Kapitalismus nur noch quantitativ unterschiedenen: auf die technische Dimension der Steigerung der Produktivkräfre. ${ }^{55}$ Schon bei Lenin ist die Tendenz hierzu angelegt. Obgleich er erkennr, daß *der Sozialismus [...] auf seine Art, mit seinen Mechoden - sagen wir konkreter, mit sowjetischen Methoden - [den] Vormarsch [zu einer höheren Arbeitsprodukrivirär] verwirklichen « ${ }^{58} \mathrm{muB}$, heißr es an anderer Steile kategorisch: "Die Arbeitsproduktivitär ist in letzter Instanz das allerwichtigste, das ausschlaggebende für den Sieg der neuen Gesellschaftsordnung. ${ }^{57}$ Dem entspricht, daß Lenin die unmittelbare Ubernahme kapitalistischer Arbeitstechnik, Taylor-System und Stücklohn propagiert. Wie im Kapitalismus soll die Direktionsgewalt im Betrieb unangetaster bleiben. Im Arbeitsprozeß soll adie unbedingte Unterordnung der Massen unter den einbeitlichen Willen der Leiter des Arbeitsprozesses ${ }^{58}$ gelten. Der Ubernahme der kapitalistischen Arbeitstechniken korrespondiert die bloße Verstaatlichung der Produktionsmittel, die mit einer Vergescllschaftung, die die kollekrive Verfügung über den Arbeirsprozeß und die gesellschaftliche Aneignung der Produkte zum Inhalt hat, nicht zu verwechseln ist; die Verstaatlichung ändert nichts an der Objektstellung der unmittelbaren Produzenten; sie sind den staatlichen Verfügungsbeamten, den Betriebsleitern, unterworfen. Lenin bezeichnete in seiner Auseinandersetzung mit den linken Kommunisten den "Staatskapitalismus\& als »einen Schritr vorwärts gegenüber der jetzigen Lage der Dinge in unserer Sowjerrepublik«, weil er die gesamtstaatliche Organisation der Produktion durch Rechnungsfübrung und Kontrolle ermögliche, ohne daß freilich die »neuen ökonomischen Zustände als sozialistisch bezeichnet « werden könnten. ${ }^{59}$ Die von Lenin eingeführte politische Kompensation für die Fortexistenz fremdbestimmter Arbeitsverhältnisse im Staarskapitalismus: die Herrschaft des Proletariats im sozialistischen Staat ${ }^{60}$ blieb durch den prinzipiellen Führungsanspruch der Partei der Bolschewiki beschränkt.

Gegen Lenins Ziel, staatskapitalistische Produktionsverhältnisse zur Entfaltung der Produktivkräfte einzusetzen, wandte sich eine Gruppe linker Kommunisten (Bucharin, Radek, Osinskij, Preobraschenski, u. a.), die im Frühjahr 19:8 in einem eigenen theoretischen Organ, »Kommunist «, ihre Kritik entwickelten. Die Abschaffung des Kapitalverhältnisses, die bei Lenin hinter die staatskapitalistisch organisierte Entfaltung der Produktivkräfte zurücktritt, rückte bei den linken Kommunisten ins Zentrum, ohne daß sie die sobjektiven Verhältnisse, namentlich die zahlenmässige und politisch-organisatorische Schwäche der Arbei-

55 Vgl. O. Neğ, Marxismus als Iegitimationswissenschaft, Einlcitung zu A. Deborin / N. Bucharin, Kontroversen über dialekrischen und historischen Marcrialismus, Frankfurt 1969, S. $30 \mathrm{ff}$. H. Marcuse, Die Gesellschaftslehre des sowjecischen Marxismus, Neuwied/Bcrlin 1964, S. $59, \mathrm{~S}_{4} 8 \mathrm{f}$.

36 W. I. Lenin, Die nächsten Aufgaben der Sowjetmacht, a. a. O., Bd. II, S. 743. Hervorhcbin: von Lenin.

57 W. I. Lemn, Die grobe Initiative, a. a. O., Bd. III, S. $26 \mathrm{r}$.

53 W. I. Lenın, Die nächsten Aufgaben der Sowjetmacht, a. a. O., Bd. II, S. 763 . Hervorhebuns von Lenis.

59 W. I. Lenin, Ober >linke Kinderei * und Kleinbürgerlichkeit, a. a. O., Bd. II, S. 786 ff.

so $\rightarrow$ Ist es nicht klar, daß wir [...] je vollständiger wir in den Sowjets den sozialistiscíten Stazt und dic Diktatur des Proletarıats verkörpert haben, um so wenıger den Staatskapitalismus zu fürchren brauchen? «, W. I. Lenin, ebenda, S. 793. 
terschaft, die sozialökonomische Rückständigkeit des Landes und die Zerrürtung der Wirtschaft übersahen.$^{b l}$ Osinskij schrieb im «Kommunist «: „Wenn man den Ubergang zum Sozialismus in der Verstaatlichung der Betriebe erblickt, bedeutet die Verstaatlichung an sich, d. h. der Ubergang eines Betricbs in Staatseigentum, noch keinen Sozialismus. In Preußen sind sämtliche Staatsbahnen in die Hände des Staates übergegangen, aber niemand glaube deshalb, daß das eine Maßnahme des Ubergangs zum Sozialismus gewesen sei. Damit die Verstaatlichung einen derartigen Sinn bekommt, ist es erstens notwendig, daß die Organisierung der Wirtschaft in den verstaatlichten Betrieben nach sozialistischen Prinzipien erfolgt, daß die Kommandogewalt des Kapitals bescitigt wird und daß der Aufbau des Betriebs keinen Boden für die Wiederbelébung dieser Kommandogewalt bietet; zweitens ist es notwendig, daß die gesellschaftliche Macht, in deren Hände das Eigentum an den Produktionsmitteln übergeht, eine proletarische Macht ist. « ${ }^{62}$ Osinskij erklärte, die mit der staatskapitalistischen Wirtschaftsform verknüpften Methoden zerstörten $\rtimes$ die Klassensolidarität der Arbeiterschaft und verwandelten diese in ein passives Element des Produktionsprozesses. Vor allem trage hierzu das System der außerordentlichen und bevollmächtigten Kommissare bei, da es jede spontane Initiative und Demokratie von unten durch eine bürokratische Zentralisation der Verwaltung ersetze. In gleicher Richtung, der Erziehung zur Passivität, wirke eine von oben oktroyierte Arbeitsdisziplin, die durch bürokratische Instirutionen überwacht werde. ${ }^{83}$ Die Kontroverse zwischen Lenin und den linken Kommunisten wurde durch den im Sommer 19I 8 beginnenden Bürgerkrieg gewaltsam entschieden: ökonomisch wie politisch ging die Leitungsbefugnis auf den zentralen administrativen Apparat über. ${ }^{84}$

Nach dem Ende des Bürgerkrieges entbrannte die yon den linken Kommunisten entfachte Diskussion um den Aufbau sozialistischer Produktionsverhältnisse aufs neue - unter dem Vorzeichen der Gewerkschaftsdiskussion auf dem X. Parteitag der Bolschewiki im März 192 r. •Die gesamte Struktur des Sow jetregimes stand in dieser Debatte zur Diskussion. «65 Während die von Trotzki repräsentierte Gruppe die Verstaatlichung der Gewerkschaften, ihre Unterstellung unter die zentrale Wirtschaftsverwaltung forderte (wie sie später unter Stalin verwirklicht wurde), plädierte die Gruppe Arbeiteropposition« (Schlapnikow, Kollontaj u. a.) für den Ubergang der Leitung des Wirtschaftsprozesses an die in den Gewerkschaften zusammengefaßten unmittelbaren Produzenten. Lenin, Repräsentant des mehrheitlichen Zentrums der Partei, das die Gewerkschaften zu "Schulen des Kommunismus machen wollte, war sich mit Trotzki - dessen Verstaatlichungsforderung er allerdings ablehnte, weil sich die Gewerkschaften dann zu einem bürokratischen Apparat verwandeln würden - darin einig, daß es gegenüber der politischen und ökonomischen Suprematie der Partei keine auronorre Selbstorganisation der Produzenten geben dürfe. ${ }^{60}$ So richtete sich der entscheidende Stoß gegen die »Arbeiteropposition «. Ihre Zielsetzung giptelte in der I3. ihrer zum Parteitag veröffentlichten Thesen: „Die Organisierung der

31 R. Lorenz, Wirtschaftspolitische Alternativen der Sowjetmacht im Frühizhr und Sommer 19 is, neue kritik 45 (Dezember 1967), S. 34.

6: N. Osinskij, Uber den Aufbau des Soz1alismus, Kommunist, Nr. I und 2/rgr8, zit. nach dem vollständigen Text in: F. Kool / E. Oberländer (Hrsg.), Arbeiterdemokratic oder Parteidiktatur, Olten 1967, S. 101 .

os R. Lorenz, a. a. O., S. 29 f.

of Ebenda, S. 45 .

os I. Deutscher, Die sowjetischen Gewerksehaften, Frankfurt 1969, S. 75 .

68 Ebenda, S. 69, S. 72, S. 80. 
Leitung der gesamten Volkswirtschaft obliegt dem Allrussischen Kongreß der in den Gewerkschaften zusammengeschlossenen Produzenten, der das zentrale Organ zur Leitung der gesamten Volkswirtschaft der Republik wählt. * ${ }^{67}$ Die Arbeiteropposition - ihre Sprecher waren durchweg erprobte bolschewistische Gewerkschafter -, ließ sich vom gleichen Impetus leiten wie die linken Kommunisten des Jahres 19r 8: „Die Gewerkschaft muß, wenn sie im Produktionsprozeß [...] das Bewußtsein der befreiten Produzenten entwickelt, die Arbeit so organisieren, daß der Arbeiter aus einem Anhängsel der toten Wirtschaftsmaschinerie zum bewußten Schöpfer des Kommunismus wird $[\ldots] . \times^{68}$ Ein derartiges "Fundament neuer Produktionsverhälenisse sei in der jetzigen ökonomischen Verfassung nicht zu erblicken: „Die Praxis der Parteizentren und der Staatsorgane hat den Tätigkeitsbereich der Gewerkschaften in den letzten beiden Jahren systematisch eingeschränkt und den Einfluß der Gewerkschaften im Sowjetstaat fast beseitigt. Die Rolle der Gewerkschaften bei der Organisierung und Leitung der Produktion ist in Wirklichkeit auf die Rolle eines Auskunf ts- oder Empfehisbüros reduziert worden, das die Verwaltungsposten mit Funktionären besetzt. « ${ }^{69}$ Alexandra Kollontaj, Wortführerin der Arbeiteropposition, rüttelte an der Avantgardefunktion der Partei, bestimmte das Verhältnis von Partei und Klasse bei der Umgestaltung der Gesellschaft gegen Lenin in der Weise Rosa Luxemburgs, die der Partei nur eine abgeleitete und keine originäre Funktion in der Selbstorganisation des Proletariats zusprach. Alexandra Kollontaj schrieb: -Die Revolution kann von der Vorhut der Klasse vollendet werden, aber die wirtschaftliche Grundlage der Herrschaft der neuen Gesellschaft kann nur von der ganzen Klasse in der praktischen Alltagsarbeit ihres wichtigsten Klassenkollekrivs geschaffen werden [...]. Den Kommunismus kann man nicht dekretieren. Er kann nur durch lebendiges Suchen, durch zeirweilige Fehler, jedenfalls aber durch die schöpferische Kraft der Arbeiterklasse geschaffen werden. « ${ }^{70}$

Lenin verwarf die von der Arbeiteropposition intendierte Selbstregierung der Produzenten. Er verwies auf die spezifische Situation des Sowjetstaates, auf die Zerrüttung des Landes, und vor allem auf die in der Ubergangsphase zum Sozialismus fortbestehenden Klassenverhältnisse, die sich von der Homogenitä: einer sich selbst regierenden Produzentengesellschaft, der kommunistischen Gesellschaft, derart unterscheide, daß eine Ubernahme der Wirtschaftsorganisation durch einen Allrussischen Kongreß der Produzenten unmöglich sei. ${ }^{71}$ Lenins prinzipielles Argument aber lautere, $\gg \mathrm{da} B$ die Diktatur des Proletariats nicht anders als durch die kommunistische Partei möglich ist. ${ }^{72}$ In der von Lenin entworfenen und vom Parteitag mit überwältigender Mehrheit angenommenen Resolution süber die syndikalistische und anarchistische Abweichung in unserer Partei« heiße es zusammenfassend zur Arbeiteropposition: "Die Idecn [der Arbeiteropposition] [... ] sind theoretisch von Grund aus falsch, denn sie bedeuten den völligen Bruch mit dem Marxismus und Kommunismus sowie mit den Ergebnissen der praktischen Erfahrungen aller halbproletarischen Revolutionen und der jetzigen proletarischen Revolution. Erstens vereinigt der Begriff

87 Vollständiger Text in: F. Kool / F. Oberländer, a. a. O., S. 177.

68 Ebenda, S. 176.

00 Ebenda, S. 176, S. 172.

io A. Kollontaj, Die Arbeiteropposition, vollständiger Text in: ebenda, S. 223. Hervorhebun: von mir.

it W. I. Lenn, Referat über die Einheit der Partei und die syndikalistische Abweichung (aui dem X. Parteitag), in: Für und wider die Bürokratie, Schriften und Briefe 1917-1923, ed. Hillmann, Hamburg 1970 , S. Ir 3 fE.

i2 W. I. Lenin, SchluQ wort zum Bericht der KPR (B) (auf dem X. Parteirag), in: ebenda, S. 97. 
,Produzent den Proletarier mit dem Halbproletarier und mit dem kleinen Warenproduzenten und gibe somit den Grundbegriff des Klassenkampfes und die Grundforderung, zwischen den Klassen genau zu unterscheiden, radikal preis. Zweitens ist die Orientierung auf dic parteilosen Massen bzw. das Liebäugeln mit ihnen [...] eine nicht weniger radikale Abkehr vom Marxismus. Der Marxismus lehrt [...]; daß nur die politische Partei der Arbeiterklasse, d. h. die kommunistische Partei, imstande ist, eine solche Avantgarde des Proletariats zu vereinigen, zu erziehen und zu organisieren, die allein fähig ist, den unvermeidlichen kleinbürgerlichen Schwankungen dieser Masse, den unvermeidlichen Traditionen und Rückfällen in zünftlerische Beschränktheit oder zünfflerische Vorurteile unter dem Proletariat zu widerstehen und die ganze zusammengefaßte Tätigkeit des Proletariats zu leiten, d.h. es politisch zu leiten, und durch das Proletariat alle werktätigen Massen zu leiten. Anders ist die Diktatur des Proletariats nicht zu verwirklichen. « ${ }^{73}$

Der Hinweis auf die besonderen Wirtschafts- und Klassenbedingungen des Sowjetstaates, die einen direkten Ubergang zu Produktionsverhältnissen assoziierter Produzenten verhinderten, erscheint gerechtfertigt, wenn allerdings auch eine allzu strikte Trennung zwischen dem Weg zum Kommunismus, der - ohne eine qualitative, die Objektsstellung der unmittelbaren Produzenten wenigstens tendenziell aufhebende Veränderung der Arbeitsverhältnisse - staatssozialistisch pianiert wird, und dem Ziel des Kommunismus unverkennbar ist. Die »ungleichzeitigen «, dem GeschichtsprozeB vorauseilenden Thesen der Arbeiteropposition « bedeuten gewiß keinen "völligen Bruch « mit dem Marxismus; ihr Ansatz, Verfügung über die gegenständlichen Arbeirsbedingungen durchs Proletariat, bezeichnet den Kern des Sozialismus. Die Partei ist demgegenüber eine abgeleitete und sekundäre Größe, die nur als unmittelbares Instrument der Arbeiterklasse ihre Legitimation besitzt. ${ }^{74} \mathrm{Um}$ es zugespitzt zu formulieren: Nicht die Herrschaft der Partei, sondern die Emanzipation des Proletariats ist das Ziel des Sozialismus.

Die uneingeschränkte Herrschaft der Partei, die Trotzki in der Diskussion des Parteitages auf die Formel brachte, daß die Partei sberechtigt wäre, ihre Diktatur selbst dann zu sichern, wenn diese Diktatur zeitweilig mit den vorübergehenden Stimmungen der Arbeiterdemokratie zusammenstößt «is, wurde zur Kernstruktur des osteuropäischen Sozialismus. Die Folgen der leninistisch aufgelösten Dialektik von Partei und Klasse sah Rosa Luxemburg schon I 9 I 8 voraus: - Das öffentliche Leben schläft allmählich ein, einige Dutzend Parteiführer von unerschöpflicher Energie und grenzenlosem Idealismus dirigieren und regieren [...] und eine Elite der Arbeiterschaft wird von Zeit zu Zeit zu Versammlungen aufgeboten, um den Reden der Führer Beifall zu klatschen, vorgelegten Resolutionen einstimmig zuzustimmen, im Grunde also eine Cliquenwirtschaft - eine Diktatur allerdings, aber nicht die Diktatur des Proletariats, sondern die Diktatur einer Handvoll Politiker, d. h. Diktatur im bürgerlichen Sinne, im Sinne der Jakobiner-Herrschaft. «78

Die parteibürokratische Tendenz, die den emanzipativen Anspruch qualitativ veränderter Produktionsverhältnisse absorbiert, führt zur Identifikation des

73 W. I. Lenin, Ursprünglicher Entwurf der Resolurion über die syndikalistische und anarchistische Abweichung unserer Partei, a. a. O., Bd. III, $66_{3} f$.

$74 \mathrm{Vgl}$. R. Rossanda, Einleitung zu: Parcei und Klasse, Berlin 1970, S. s ff.

75 L. Trotzki zit. nach I. Deutscher, Die sowjetischen Gererkschzfren, a. a. O., S. 78 . Vgl. auch $W$. I. Lenin: Produktion ist immer nötig, Demokratie nicht.e In: Hillmann, a. z. O., Uber die Gewerkschaften, die gegenwärtige Lage und die Fehler des Genossen Trorzki, S. 74.

76 R. Luxemburg, Die russische Revolution, 2.2.0., S. 75 . 
Aufbaus des Sozialismus mit der Steigerung der Produktivkräfte. Dies wird auf dem XI. Parteitag der Bolschewiki vom März 1922 besonders deutlich. In der entscheidenden von Lenin formulierten Entschließung heißt es: "Nach der Eroberung der Staatsmacht bestcht das wichtigste und grundlegendste Interesse des Proletariats in der Vergrößerung der Produktionsmenge und gewaltigen Steigerung der Produktivkräfte der Gesellschaft [...]. Ein solcher Erfolg [der Wiederherstellung der Großindustrie] erfordert seinerseits, bei der gegenwärtigen Lage Rußlands, unbedingt die Konzentration der gesamten Machtfülle in den Händen der Betriebsleitungen [...] Jede unmittelbare Einmischung der Gewerkschaften in die Leitung der Betriebe muß unter diesen Umständen als unbedingt schädlich und unzulässig betrachtet werden. "77 Eine derartige technizistische Reduktion des Sozialismus hatte Alexandra Kollontaj kritisiert: „Ohne die Einführung grundlegender Neuerungen im System der Leitung und Organisierung der Produktion [würde Sowjetrußland] in seiner Entwicklung nur die kapitalistischen Länder einholen. $\times{ }^{79}$

\section{Elemente des Stalinismus}

Im Stalinismus kulminierten die Tendenzen gegen eine auch nur ansatzweise Selbstregierung der Massen. Schon 1926 hatten die Opponenten Stalins (Sinowjew, Kamenew, Krupskaja, Trotzki u. a.) die Aufsaugung des öffentlichen Lebens durch eine verselbständigte "parteibürokratische Oberschichte, 782 die Entwicklung zur Seibstherrschaft diagnostiziert: „Eine wirkliche Disziplin wird zerrürter und ersetzt durch Unterwerfung unter einflußreiche Personen des Apparates [...] Das bürokratische Regime frißt sich wie ein Rost ein in das Leben jedes Betriebs und jeder Abteilung. Wenn die Parteimitglieder tatsächlich nicht das Recht haben, die Bezirksleitung, die Gruppenieitung oder das ZK zu kritisieren, so haben sie im Betrieb nicht das Recht, ihre nächste Obrigkeit zu kritisieren. « $^{i \varepsilon b}$ Die öffentlicher Kontrolle und Diskussion entzogene Herrschaft der parteibürokratischen Oberschicht, abgesichert durch das Terrorinstrument der Geheimpolizei, das gegen die alten Kader der Bolschewiki eingesetzt wird, ließ die Selbstorganisationsformen der Sowjets vollends zur Farce herabsinken. $\gg D$ ic Bevölkerung wählt die von den Parteizirkeln zuvor bestimmten Kandidaten $[\ldots]$ So kann man sagen, daß die Macht der Sowjets bei uns nur in dem besonderen Sinn existiert, daß die Oberschicht der Partei das Land im Namen der Sowjets beherrscht. «79 Aus der Diktatur des Proletariats wurde, wie Brecht im Gespräch mit Benjamin sagte, eine "Diktatur über das Proletariat ${ }^{80}$; die politische Form für die ökonomische Befreiung des Proletariats war abgestorben.

$Z$ wischen Politik und Okonomie bestand, da der Staat Eigentümer der Produk-

i7. I. Lenin, Ober die Rolle und die Aufgaben der Gewerkschaften unter den Verhältzissen der Neuen Okonomisehen Politik, a. a. O., Bd. III, S. 748 f.

is A. Kollontaj, a. a. O., S.:20. Hervorhebungen von mir. Zu den hieraus folgenden Veräncंerungen im Uberbau vgl. K. Korseh, Zur Geschichte der marxistischen Ideologie in Ruüland. Der Gegner, 1932, Nr. 3, S. $g$ ff. und besonders H. Mareuse, 2. 2. O., S. 122 ff., S. ig8 ff.. S. $23 \mathrm{ff}$.

iga Dieser Terminus nach E. S. Varga, Der russisehe Weg zum Sozialismus und seine Ergebnisse, in: Sowjerunion und China - zwer Modelle des sozialistischen Aufbaus, München 970 , S. 31 .

780 Erklärunz der Dreizehn - An die Mirglieder des ZK und des ZKK, in: G. Hillmann (Hrss.). Selbstkritik des Kommunismus, Hamburg 1967, S. 113, S. x1s. Hervorhebung durch die Verfasser.

70 E. S. Varga, a. 2. O., S. 4 1.

so W. Benjamin, Versuche über Breche, Frankfure 1966, S. 135. 
tionsmittel war, eine vollständige Fusion. ${ }^{81}$ Die unmittelbaren Produzenten blieben von den verstaatlichten Produktionsmitteln, über welche die parteibürokratische Oberschicht verfügte, getrennt: „Vor allem ist es notwendig «, erklärte M. M. Kaganowitsch, ein Senior-Vertreter des Kommissariats für die Schwerindustrie, "die Ein-Mann-Leitung zu stärken. Es ist notwendig, von der grundlegenden Auffassung auszugehen, daß der Direktor der höchste Chef der Fabrik ist. Alle in der Fabrik Beschäftigten müssen ihm vollständig untergeordnet

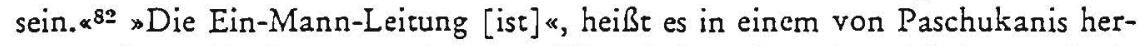
ausgegebenen Buch zum sowjetischen Wircschaftsrecht, »das wichtigste Prinzip der Organisation der sozialistischen Wirtschaft. « ${ }^{83}$ Das Arbeitsverhälnis wurde quasi-militärisch geordnet, die Arbeiter durch ein drakonisches Strafensystem gefesselt. Ein am 18. Dezember 1938 veröffentlichter Erlaß, unterzeichnet von Stalin, Molotow und Schwernik, bestimmte z. B., daß Arbeiter, die ihre Arbeitsstellen ohne Erlaubnis verließen oder sich ernster Vergehen gegen die Arbeitsdisziplin schuldig machten, »verwaltungsmäßigen $Z_{\text {wangsausweisungen }}$ (aus ihren Wohnungen) innerhalb von ro Tagen unterlagen, ohne daß ihnen Wohnungen zur Verfügung gestellt wurden $\times .{ }^{84}$ „Da Häuser in der Regel Eigentum der Gemeinden oder Stadtbehörden waren, besaß der [...] Ausgewiesene praktisch keine Möglichkeit, eine neue Unterkunft zu erhalten. Dies hatte häufig


begann nun diejenige Rolle zu spielen, die die Furcht vor Arbeitslosigkeit unter dem Kapitalismus gespielt hatte: sie hielt die Arbeitsdisziplin aufrecht. «85 Mit dem Stichwort "sozialistischer Wettbewerb», besonders ausgeprägt im »Stachanowismus «, der die Arbeiter durch ein ausgeklügeltes Akkordsystem dissozïerte und die »besten Vertreter« mit Privilegien bedachte, wurde gleichzeitig eine starke Differenzierung der Löhne durchgeserze. ${ }^{86}$ Die Gewerkschaften degenerierten zu Transmissionsriemen der parteibürokratischen Oberschicht. Nicht zufällig fand I7 Jahre lang zwischen I 932 und I 949 kein Gewerkschaftskongreß statt. ${ }^{87}$ Im Rahmen dieser repressiven Arbeitsverhältnisse fungierte die gesamtwirtschaftliche Planung, institurionalisiert in den Fünf-Jahresplänen, als bürokratische Konstruktion von oben, die den unmitrelbaren Produzenten als frem-

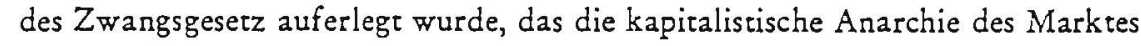
durch die Dezision der Parteizentrale ersetzte. ${ }^{88}$

Die ökonomische und politische Hörigkeit der unmittelbaren Produzenten wurde zur Basis des Industrialisierungsprozesses in der Sowjetunion. Dicser $\mathrm{Zu}$ sammenhang wird allzuleiche zur mechanistischen Notwendigkeit verkürzt. Schon das Beispiel Jugoslawiens, das mit Hilfe des die Selbständigkeit der unmittelbaren Produzenten mobilisierenden Systems der Arbeiterselbstverwaltung seit 1950, ungeachtet schwach entwickelter Produktivkräfte, die Industrialisierung betreibt, ${ }^{80}$ zeigr, daß von einer gleichsam meta-geschichtlichen Norwen-

81 Vgl. T. Cliff, Russia a Marxist Analysis, London 1970', S. 125 f.

82 Sa Industrialisaziu (Organ des Kommissariass für die Schwerindustrie), Moskau I6. 4. 1934, zit. nach T. Cliff, a. 2. O., S. 19.

83 L. Gintsburs / E. Paschukanis, Leitfaden des sowjetischen Wirtschaftsreches (russisch), Moskau 1935, Vol. 1, S. 8, zit. nach T. Cliff, ebenda, S. 19.

86 I. Deurscher, Die sowjetischen Gewerkschaften, Frankfurt 1969, S. II 3 f.

as Ebenda, S. r14, $7 \mathrm{gl}$. auch zu weiteren Einzelheitcn der stalinistischen Arbeitsverfassung: W. Hofmann, Die Arbeitsverfassung der Sow jetunion, Berlin 1956, S. $225 \mathrm{ff}$.

so I. Deutscher, a. 2. O., S. IzI ff.

a7 Ebenda, S. 147.

88 Vg!. C. Bettelheim, Okonomischer Kalkül und Eigentumsformen, Berlin 1970.

so Vgl. H. Roggemann, Das Modell der Arbeiterselbstrerwaltung in Jugosiawien, Frankfurt 1970. Die durch die Selbsttätigkeit der unmittelbaren Produzenten vermittelte Industriali- 
digkeit nicht gesprochen werden kann. Das Geflecht stalinistischer Verformungen war das Resultat besonderer Bedingungen: Zum einen niche überwundener »Zarismen , die Lenin mit dem Satz bezeichnete, daß der Staatsapparat nnur äußerlich leicht übertüncht worden [ist], im übrigen aber [...] etwas typisch Altes aus unserem alten Staatsapparat [darstellt] « ${ }^{80}$; hinzutrat die weltpolitische Isolierung der Sowjetunion, verbunden mit der latenten Interventionsdrohung kapitalistischer Staaten, die dazu zwang, die Produktivkräfte durch Rüstungsinvestitionen zu fessein: das Ausbleiben der internationalen Revolution behinderte die emanzipative Oberwindung der Rückständigkeit des Sowjetstaates; als systematische Ursache erscheint schließlich die gleichsam staatsrechtlich sanktionierte Leninsche Parteidoktrin, die die Usurpation des Parteiapparats durch das Generalsekretariat Stalins direkt begünstigte.

Die aus diesen Bedingungen hervorgegangenen Herrschaftsverhältnisse wurden von Stalin zum "vollen Sieg des sozialistischen Wirtschaftssystemsa ideologisiert, das die "Ausbeutung des Menschen durch den Menschen « beseitigt habe. ${ }^{91}$ Demgegenüber ist mit Trotzki daran festzuhalten, da $B$ das $»$ Sowjetregime in allen seinen Widersprüchlichkeiten nicht als sozialistisches, sondern als vorbereitendes oder Ubergangsregime zwischen Kapitalismus und Sozialismus zu bezeichnen « ist, ${ }^{92}$ das, ungeachtet seiner repressiven Gesamtverfassung, dank der zentral gesteuerten Investitionspolitik eine cum grano salis wohlfahrtsstaatliche Entwicklung der Infrastruktur (Bildungs- und Gesundheitswesen etc.) ermöglichte. Die ambivalente Verfassung des stalinistisch organisierten Sowjetstaates, der, obgleich er die formalen Voraussetzungen des Sozialismus (Abschaffung des kapitalistisch fungierenden Eigentums/gesamtwirtschaftliche Planung) verwirklichte, dessen emanzipativen Anspruch in terroristischen, parteibürokratischen Herrschaftsverhältnissen begrub, hat Brecht klar bezeichnet. In seiner Schrift *Me-ti-Buch der Wendungen « heißt es: "Der Besitz der Einzelnen an Arbeitsmitteln ist abgeschafft, und indem auch die Erde als ein solches Arbeitsmittel betrachtet wird und der Einzelbesitz an Erde abgeschafft ist, verschwinder der Gegensatz von Stadt und Land, denn auch die Erde kann jetzt auf große planmäßige Weise bebaut werden. Aber das neue System, das fortschrittlichste der Weltgeschichte, arbeitet noch sehr schlecht und wenig organisch und braucht soviel Anstrengung und Gewaltanwendung, daß die Freiheiten der Einzelnen sehr gering sind. $\mathrm{Da}$ es von geringen Einheiten von Menschen erzwungen wird, gibt es überall $Z$ wang und keine richtige Volksherrschaft. Die Meinungsunfreiheit, Koalitionsunfreiheit, Lippendienerei, die Gewalttaten der Magistrate beweisen, daß noch lange nicht alle Grundelemente der großen Ordnung [d. h. des Sozialismus] verwirklicht sind und verwirklicht werden. ${ }^{93}$

sierung ist allerdings durch die gleichzeitige Einführung des Marktmechanismus mic kapitaliscischen Friktionen beiastet. - Zu der Industrialisierung in China, die sich von der sowjerischen der $30 e r$ Jahre offenbar durch größere Initiative der Massen unterseheidet, $\mathrm{rgl}$. C. Betteiheim, China und dic Sowjerunion: Zwei $\rightarrow$ Modelles der Industrialisierung, in: Sowjerunion und China, a. a. O., S. so ff. und C. Betrelheim, u. 2., Der Aufbau des Sozialismus in Chinz, München 1969 .

20 W. I. Lenin, Wie wir die Arbeiter- und Bauerninspektion reorganisieren sollen, 2. a. O., Bd. III, S. $87 \mathrm{r}$.

a1 J. W. Stalin, Rechenschaftsbericht an den XVIII. Parteitag über die Arbeit des ZK der KPdSU (B), in: Schriften zur Ideologie der Bürokratisicrung, ed. Hillmann, Hamburg 1970, S. 217,221 .

92 L. Trotzki, Verracene Revolution, Zürich o. J. (1957), S. 49.

93 B. Brecht, Me-ti - Buch der Wendungen, Frankfurt 1965, S. 138 f. Hervorhebung von Brecht. Die gegenwärtige politische Verfassung der Sowjetunion konnte im Rahmen dieser Vorstudie nicht untersuche werden. Zur gegenwärtigen Strukeur der Sowjetunion vgl. et $w 2$ die Darstellung von H. Conert, a. a. O., S. 8I ff. m. w. Naciw., sowie speziell für die Produk- 
Die Erfahrungen mit den staatssozialistischen Verformungen im Stalinismus ließen, als bestimmte Negation, Modelle der politischen Verfassung des Sozialismus entstchen, die sich mehr oder minder ausdrücklich auf die zentrale Marxsche Intention, die Abschaffung des Kapitalverhältnisses und die damit verknüpfte Aufhebung der politischen Gewalt, berufen. Von den verschiedenen theoretischen und praktischen Ansätzen in Osteuropa sei exemplarisch der tschechoslowakische Reformkommunismus des Jahres 1968 betrachtet.

Die praktische Kritik setzte in der CSSR direkt am politischen Herrschaftssystem an. Seine Struktur analysierten die Reformer in folgender Weise: "Das Vorjanuar-System war gekennzeichnet durch eine tiefe, hierarchisch abgestufte politische Ungleichheit zwischen der kleinen Gruppe wirklich herrschender Personen, den Beamten der diversen Apparate, dem Funktionärsaktiv und schließlich den breiten Schichten der Bevölkerung (Kommunisten und anderen Bürgern), die an der Leitung der Gesellschaft nicht wesentlich mitwirken konnten. « ${ }^{94}$ "Der Sozialismus [...] wurde reduziert auf die Verstaatlichung des kapitalistischen Eigentums, auf administrativ direkte Wirtschaftsleitung vom Zentrum aus und auf ein monopolistisches machtpolicisches System. Das ist jedoch noch kein Sozialismus. Innerhalb dieser Grenzen des gesellschaftlichen Iebens vermag weder die Arbeiterschaft noch die Bauernschaft und die Intelligenz sich als Schöpferin neuer zwischenmenschlicher Beziehungen zu entfalten. «95 Liberale Freiheitsrechte (Vereinigungsfreiheit, Koalitionsfreiheit, Meinungsfreiheit, Pressefreiheit) sollten den Herrschaftsapparat »demokratisieren *, ihn in eine massen mobilisierende Offentlichkeit, die zum Artikulationsorgan der Selbstregierung wird, zurückzuholen - entsprechend der (etwas verschwommenen) Formulierung des Aktionsprogramms der KPC vom 5. April 1968: „Der Sozialismus kann niche nur die Befreiung des arbeitenden Volkes von der Vorherrschaft der ausbeutenden Klassenbeziehungen bedeuten, sondern muß mehr als jede andere bürgerliche Demokratie ermöglichen, die Persönlichkeit des Einzelnen voll zur Geltung zu bringen. «\$0 Das Zurückgreifen auf liberale Freiheitsrechte ist als Rückfall in überholte bürgerliche Rechrsformen begriffen worden: »Die nachstalinistische Reform in der CSSR stellte eine ahistorische Uberführung des geschichrlich neuen, noch unentfalteten und etatistisch verstümmelten Prinzips der sozialistischen Produktionsweise in die alte und abgestorbene Substanz bürgerlicher Verkehrsformen dar [...] als sweltgeschichtliche Totenbeschwörung (Marx) des fossilierten Liberalismus der längst untergegangenen konkurrenzkapitalistischen Phase der bürgerlichen Gesellschaft - als Versuch rechtsstaatlicher Institutionalisicrungen republikanischer Freiheiten. ${ }^{07}$ Eine derartige ab-

tionsverhäitnisse L. Foa, Einleitung zu I. Deutscher, Die sowjerischen Gewerkschaften, a. a. O., S. $s$ ff. und L. Foa, Der neue Wirtschaftskurs, in: P. Strotmann (Hrsg.), zur Kritik der Sowjetökonomie, Berlin 1969, S. 152 ff.

24 Analyse der Parteteätigkeıt und der gesellschaftlichen Entwicklung seit dem I3. Parteitag und dic Hauptaufgaben der Partei (Materialien für den 14. Parteitag der KPC, der am 22. 8. 1968 in Prag als Untergrundsparteitag stattíand), in: J. Pelikan (Hrsg.), Panzer überrollen den Parteitag, Protokoll und Dokumente des 14. Parteitags der KPC 2m 22.8. 1968, Wien/ Frankfurt/Zürich 1969 , S. 196.

os Uber dic Vorbereitung und Grundzüge eines langfristigen Parteiprogramms (Materialien für den I4. Parteitag der KPC), ebenda, S. r 20.

so Volkszeitung (Prag) v. 19. 4. I968. Vgl, auch O. Negt, Das Ende des Sralinismus, in: Prag und die Linke, Hamburg r 968 , S. 27.

$17 \mathrm{H}$. j. Krahl, Zur historischen Dialektik der nachstalinistischen Reform, Einleitung zu: R. Deppe, u. a., Die Tschechoslowakei 1945-1968 - Zwischen Kapitalismus und Revolution, Frankfurt/Berlin 1968, S. 7, S. 11. Vgl. aber ebenda, S. 14: >Die Erfahrungen gerade der 
strakt-puristische Kritik wirft das emanzipative geschichtliche Erbe der Französischen Revolution auf den Kehrichthaufen der Geschichte, statt zu erkennen, daß im Sozialisnus die bürgerlichen Freiheiten, in "umfunktionierte[r] Konsequenz «88, endlich, ohne Paralysierung durch ökonomische Ungleichheit, inhaitlich realisiert werden können. Rosa Luxemburg faßte diese Einsicht in den programmatischen Satz: wir unterscheiden stets den sozialen Kern von der politischen Form der bïrgerlichen Demokratic, wir enthüllen stets den herben Kern der sozialen Ungleichheit unter der süßen Schale der formalen Freiheit und Gleichheit - nicht um diese zu verwerfen, sondern um die Arbeiterklasse dazu anzustacheln, sich nicht mit der Schale zu begnügen, vielmehr dic politische Macht zu erobern, un sic mit neuem Inhalt zu füllen. « ${ }^{9 \theta}$ Allein sozialistische Demokratie - das war der strategische Sinn der These Rosa Luxemburgs - kann verhindern, daß die Selbstregierung des Proletariats zur Herrschaft einer unkontrollierbaren und unkritisierbaren parteibürokratischen Oberschicht (die sich schließlich mit dem Spruch "Die Partei hat immer recht « gegen die potentieile Sclbsttätigkeit der Unteren impfte) verkommt. Dies hatte die KPC erkannt. Im Aktionsprogramm hieß es: $»$ Die kommunistische Partei stützt sich auf die freiwillige Unterstützung durch die Menschen. Sie verwirklicht ihre führende Rolle nicht dadurch, daß sie die Gesellschaft beherrscht, sondern dadurch, daß sie der freien, fortschrittlichen und sozialistischen Entwicklung am treuesten dient. Sie kann sich ihre Autorität nicht erzwingen, sondern muß sie immer aufs Neuc durch ihre Taten gewinnen [...] Die führende Rolle der Parrei wurde in der Vergangenheit of́t als Monopol, als Konzentration der Macht in der Hand der Parteiorgane aufgefaßt. Das entsprach der falschen These, daß die Partei das Instrument der Diktatur des Proletariats sei.«100 Die progressive Funktion der Prager Reformer bestand darin, die Partei, die den Stastsapparat in unbeschränkter Verfügungsmacht beherrscht hatte, aus ihrer geschichtsmythologischen Unfehlbarkeit zu befreien, sie auf die Ebene öffentlicher Diskussion und Kontrolle zurückzuholen.

Im Rahmen einer emanzipativen politischen Verfassung, die Selbstorganisationsformen der Massen sich entwickeln läßt, konnte die ökonomische Befreiung der unmittelbaren Produzenten, die in dem etatistischen Vorjanuar-System von den verstaatlichten Produktionsmitteln getrennt bleiben, wieder ins Zentrun: rücken. Selbstverwaltungsorgane - insbesondere Arbeiterräte - sollten als Form des "allmählichen langfristigen Absterbens staatlicher Macht und Repression «101 fungieren. Mit der Rückbesinnung auf die zentrale Marxsche Intention konnte auch die technizistische Reduktion des Sozialismus auf die Steigerung der Produktivlsräfte überwunden werden: $» D i e$ Industrialisierung, die sici: vorwiegend auf das extensive Wachstum der industriellen Produkrivkräfte (Maschinen- und Arbeitskräfte) stützt, zählt nicht zu den historischen Aufgaben des Sozialismus, sondern vielmehr zu seinen Voraussetzungen, sie stellt sogar einen Zivilisationsprozeß dar, der zur eigentlichen Entwicklung des Sozialisnus in:

ersten Okkupationstage in der CSSR haben gezeigt, daß in einem Land mit staztici::: Authebung [des Privateigentums an Produktionsmiteln] die republikanischen Freihaten wicder in alierdings geschichtlich neuer Weise dem Proletariat die organisatorischen Bedincun. gen für die Fortsetzung des revolutionären Klassenkampfes im sozialistıschen Lager selbs: liefern können. \&

o8 E. Bloch, Politische Miessunger, Frankfure 1970, S. 365. Zur Einzelableirung vgl. E. Bloc:: Naturrecht und menscriliche Würde, Frankfurt r96r, S. 200 ff.

99 R. Luxemburg, Die russische Revolution, 2. a. O., S. 78 . Hervorhebung von Luxemiurg.

100 Volkszestung (Prig), a. 2. O.

101 Uber die Vorbereırung und Grundzüge eines langfristigen Parteiprogramms, a. a. O., S. I:2. 
Widerspruch steht. Solange die Gesellschaft die Produktion um den Preis einer gewissen Einschränkung der Konsumentwicklung (für die Mehrheir) entfalter, solange sie die Produktivkräfte durch Vermehrung der einfachen Industricarbeit crweitert, solange sie wissenschaftliche Leitung in dem Sinn einführt, daß der Mehrheit die Teilnahme an der Lcitung verwchrt bleibt, [...] solange also die allgemeine Entwicklung eine Einschränkung der Entwicklung für die Mehrhøit der Arbeitenden erfordert, solange besteht renig Hoffnung, daB die zwischenmenschlichen Beziehungen - trotz Aufhebung der Ausbeutung - vahrhaft sozialistischen Charahter annehmen. «102

Die ökonomische Befreiung der unmittclbaren Produzenten sollte allerdings mit der Wiedereinführung von Marktmechanismen, die die zentralen staatlichen Direlitiven ersetzen, um »die unternehmerische Initiative der Werktätigen zu mobilisicren «, ${ }^{103}$ gekoppel werden. Damir war die Selbstrcgierung der Produzenten begrenzt auf das einzelne isolierte Unternehmen: die Aufhebung des Kapitalverhältnisses wird travestiert zur Verwandlung der Arbeiter in Kapitalisten, die als gegeneinander konkurrierende Gruppeneigentümer fungieren; dis unmittelbaren Produzenten wären weitez an den Fetischcharakter der Warenproduktion gekettet, welche die Arbeiter nur als dissoziierte Konkurrenten in Beziehung treten läßt. Die "sozialistische Marktwirtschaft « erscheint als abstrakte Negation des Stalinismus, die den Plan als prinzipiell unveränderliche, bürokratisch-etatistische Konstruktion von oben verwirft. So wird die konkrete Aufarbeitung des Stalinismus in der Form eines gesamtgesellschaftlichen Plans, der zum Instrument der assozïerten Individuen würde, die die Produkrivkräfte bewußt für die Befriedigung menschlicher Bedürfnisse einserzen, ausgekreist. ${ }^{104}$ Die abstrakte Negation des Stalinismus läßt hinterrücks dessen technokratische Perspektive, die die Steigerung der Produktivkräfte an die Stelle der Veränderung der Produktionsverhältnisse treten ließ, wiedererstehen: Allein aus Effizienzgesichtspunkten sollte die »sczialistische Marktwirtschaft " eingeführt werden. ${ }^{105}$

Im Rahmen eines tauschgesellschaftlich organisierten Untcrbaus verwandelt sich leicht die politische Verfassung aus einer Form für die ökonomische Befreiung zu einem rechtfertigenden Uberbau, der die unmittelbaren Produzenten ideologisch in ihrer entfremdeten Konkurrenzsituation befestigt. Trotzdem ist die ambivalente Rolle der politischen F̈reiheitsrechte, die prinzipiell auch die Artikulation des Interesses an der ökonomischen Emanzipation crmöglichen, nicht zu

102 Ebenda, S. I $30 \mathrm{f}$.

103 Ebenda, S. 127.

1c.4 Vgl. C. Bettelheim, Okonomischer Kalkül und Eigentumsformen, a. a. O., S. I9, S. 8 s. Der Grad der tatsächlichen Koordination (also der Grad der Angemessenheit, der sich im Wirken des Wirtschaftsplans zeıgt) hängt [...] prinzipicll weder von der, Planungszechnike noch von detaillierten und ausgetüftelcen sadministrativen Aktionens $[\ldots]$ ab. Er hängt ab von objektiven politischen Bedingungen (von der tarsächlichen Teilnahme der Massen an der Ausarbeitung und Durchführung der Pläne) und von wissenschaftlichen Bedingungen (der Plan koordiniert nur dann wirksam die Aktivitäten der verschiedenen Produktionseinheiten, wenn er auf einer wissenschaftlichen Analyse der ökonomischen und gesellschaftlichen Wirklichkeit beruhe und wenn cr den Anforderungen der wissenschaftlichen Erprobung genügt). Die zweicen Bedingungen können [...] nur realisiert werden, soweit die ersten realisiert sind; die Kennenis der ökonomischen Wirklichkeit und die wissenschaftliche Erprobung auf gesellschafelicher Ebene[. . . bilder sich nur heraus unter der Tcilnahme der Massen. . Ebcnda, S. $54 \mathrm{f}$.

acs Vgl. den Abschnite über Wirtschaftsfragen in Aktionspronramm der KPC v. s. 4. I968, Volkszeıtung, a. a. O. Zur Reform des ökonomischen Systems der CSSR vg!. im übrigen E. Alrvater, C. Neusüss, Bürokratische Herrschaft und gesellschaftliche Emanzipacion, ncue kricils si/g2 (Februar 1969), S. ig ff. 

nichtet.

\section{Schin $\beta$}

Die politische Form für die ökonomische Befreiung des Proletariats muß die Emanzipation der Klasse betrciben. Die Partei, mögliche Form der Vermittlung von Theoric und Praxis, kann für dieses Ziel nur Instrument sein. Schon die Organisationsform des Proletariats im Kampf gegen den Kapitalismus muß sich vom Ziel einer assoziierten Produktionsweise her bestimmen. Sobald die Partei eine originäre Funktion gegenüber dem Proletariat bekommt, ist die Degeneration des Sozialismus zu einem etatistischen System gesetzt. Dessen Kritik ist eine Bedingung für die Konstitution der Neuen Linken, die sich vom Zentrum der Marxschen Theorie, der Ersetzung des Kapitalverhältnisses durch einen "Verein freier Menschen ", leiten läßt.

106 Vgl. die Ansätze linker Gruppen in Prag, in: M. Borin/V. Plogen, Managemene und Selbstverwaleung in der CSSR, Berlin 5970 , S. 106 ff. - Realpolitisch gesehen unterschärz:en die Reformer die strategische Rolle der CSSR in der Konkurrenz der Weitsysteme, bezogen dic außenpolitischen Interessen der Sowjerunion, von denen man so oder so niche absenen konnte, niche genügend in ihr Kalkül ein. Daß die Intervention vom 25 . Auguse 1968 nicht nur der auBenpolitischen Absicherung des sozialistischen Lagerse diente, sondera auch die innenpolitische Schutzfunktion gegen ein Obergreifen seibsttz̈tiger sozialistischer Organısationsformen auf die übrigen -sozialiseıschen Länder hatte, zeigt die gegenwärtige Repressionsveriassung der CSSR, die sich z. B. im sogenannten Trozzkisten-Prozeß, im Zurückdrängen der Rehabilitierung von Personen, die staliristischen Prozessen zum Opfer fielen, und is: der rigorosen Ausschaltung kritischer sozizlistischer Intelligenz aus dern öffentlichen Leben ausdrückt. 